\title{
Configurações
}

Revista de sociologia

$24 \mid 2019$

Imaginar "futuros" do trabalho, contextos e vivências subjetivas

\section{O futuro do trabalho entre as vozes da academia e as perspetivas sindicais}

The future of the work between the voices of the academy and trade union perspectives

L'avenir du travail entre les voix de l'académie et les perspectives syndicales

\section{Hermes Augusto Costa}

\section{(2) OpenEdition}

\section{Journals}

\section{Edição electrónica}

URL: http://journals.openedition.org/configuracoes/7638

DOI: $10.4000 /$ configuracoes.7638

ISSN: 2182-7419

Editora

Centro de Investigação em Ciências Sociais

Edição impressa

Paginação: 11-27

ISSN: 1646-5075

\section{Refêrencia eletrónica}

Hermes Augusto Costa, «O futuro do trabalho entre as vozes da academia e as perspetivas sindicais », Configurações [Online], 24 | 2019, posto online no dia 10 janeiro 2020, consultado o 10 janeiro 2020. URL : http://journals.openedition.org/configuracoes/7638; DOI : 10.4000/configuracoes.7638 
Costa, Hermes Augusto - 0 futuro do trabalho entre as vozes da academia e as perspetivas sindicais. Configurações, vol. 24, 2019, pp. 11-27.

\title{
O futuro do trabalho entre as vozes da academia e as perspetivas sindicais ${ }^{1}$
}

\author{
HERMES AUGUSTO COSTA *
}

Faculdade de Economia, Centro de Estudos Sociais - Universidade de Coimbra

\begin{abstract}
Resumo
Após uma sistematização teórica breve de alguns debates sobre o futuro do trabalho, os quais podem ser condensados sob a forma de um confronto de posições (mais críticas/ pessimistas versus mais tolerantes/otimistas), este texto fornece duas ilustrações empíricas daí decorrentes. Por um lado, apresenta-se uma experiência pedagógica inédita no espaço universitário europeu inspirada nos diálogos do centenário da OIT. Por outro lado, em resultado de um projeto de investigação, expõem-se algumas perceções de sindicalistas sobre o futuro do trabalho. Da experiência pedagógica sobressai uma visão propositiva e ousada dos jovens, ao passo que da visão dos responsáveis sindicais ecoa um maior pessimismo (mormente sobre o desafio tecnológico). Ainda assim, ambas as visões parecem convergir na necessidade de perspetivar o futuro do trabalho com base em imperativos regulatórios de sentido emancipatório.
\end{abstract}

Palavras-chave: futuro do trabalho; perceções de jovens universitários; olhares sindicais; indústria 4.0; regulação.

\footnotetext{
1 Este trabalho tem o apoio financeiro da Fundação para a Ciência e Tecnologia (FCT/MEC) através de fundos nacionais e é cofinanciado pelo FEDER através do Programa Operacional Competitividade e Inovação COMPETE 2020 no âmbito do projeto "Rebuilding trade union power in the age of austerity: a review of three sectors" (PTDC/IVC-SOC/3533/2014 - POCI-01-0145-FEDER-016808).

*E-mail: hermes@fe.uc.pt
} 


\begin{abstract}
The future of the work between the voices of the academy and trade union perspectives After a brief theoretical systematisation of a series of dual-sense debates that frame the future of work, this text provides two resulting empirical illustrations. On the one hand, it presents an unprecedented educational experience in the European university space inspired by the ILO's centennial dialogues. On the other hand, as a result of a research project, some perceptions of trade unionists regarding the future of work are discussed. In spite of the more daring proposition of young people, which contrast with the greater pessimism of trade union leaders (especially in regards to the technological challenge), both views seem to converge on the need to prospect the future of work based on regulatory imperatives of emancipatory meaning.
\end{abstract}

Keywords: debates on the future of work; perceptions of young university students; trade union perceptions; industry 4.0 ; regulation.

\title{
Résumé
}

\section{L'avenir du travail entre les voix de l'académie et les perspectives syndicales}

Après une brève systématisation théorique de quelques débats à double sens qui encadrent l'avenir du travail, ce texte fournit deux illustrations empiriques. D'une part, nous présentons une expérience pédagogique sans précédent dans l'espace universitaire européen inspirée des dialogues du centenaire de l'OIT. De l'autre, à la suite d'un projet de recherche, certaines perceptions des syndicalistes quant à l'avenir du travail sont exposées. Bien que la proposition plus audacieuse des jeunes s'oppose à un pessimisme accru des dirigeants syndicaux (en particulier en ce qui concerne le défi technologique), les deux points de vue semblent converger sur la nécessité de prospecter l'avenir du travail sur la base des impératifs réglementaires ayant un sens émancipateur.

Mots-clés: débats sur l'avenir du travail; perceptions des jeunes étudiants universitaires; perspectives des syndicats; industrie 4.0 ; règlement.

\section{Introdução}

O ano de 2019 assinala o centenário da principal organização de governação global mais diretamente relacionada com os temas e preocupações do mundo do trabalho: a Organização Internacional do Trabalho (OIT). Criada em 1919 na sequência do Tratado de Versalhes que pôs termo formal à I Guerra Mundial, a OIT é uma referência na luta pela regulamentação das relações laborais à escala mundial, no sentido de garantir menos assimetrias entre os vários protagonistas do mundo do trabalho. As suas convenções são o melhor testemunho desse compromisso normativo no sentido de dignificar o trabalho. De resto, a agenda do "trabalho decente" à escala global foi corporizada na "Declaração da OIT sobre os princípios e direitos fundamentais no trabalho e 
seu acompanhamento" (1998) e tem continuidade, em tempos mais recentes, no objetivo 8 ("Trabalho Digno e Crescimento Económico") da Agenda 2030 das Nações Unidades para o Desenvolvimento Sustentável.

Mas não obstante o fator "trabalho" clamar por reconhecimento e dignidade, são recorrentes os episódios de distanciamento face a um qualquer "tipo ideal” de trabalho. Não é por acaso, de resto, que são frequentemente colocados em confronto discursos mais otimistas face a perspetivas mais pessimistas sobre o trabalho.

Após esse breve "quadro dual" que informa as visões sobre o futuro do trabalho, o meu principal propósito é o de, ao partir da exposição de um conjunto de cenários e propostas sobre o futuro do trabalho - apresentados sobre a forma de "diálogos do centenário" - iniciados na sequência da $104^{a}$ edição da Conferência Internacional do Trabalho (CIT) realizada em 2015 (Ryder, 2015) -, colocar em confronto dois tipos de perspetivas, resultantes, respetivamente, de uma experiência pedagógica (com jovens universitários) e de um projeto de investigação (sobre formas de poder sindical). Por um lado, confere-se destaque a uma perspetiva académica, vertida no modo como, no ano letivo de 2016/2017, 300 estudantes da universidade de Coimbra de três ciclos de estudos (mas essencialmente de licenciatura) participaram naquela que foi a primeira simulação da uma CIT realizada em meio universitário na Europa. Por outro lado, realça-se o posicionamento de velhos atores sobre o futuro do trabalho, com destaque para as atitudes sindicais sobre os impactos das novas tecnologias no trabalho, por sinal um dos diálogos de centenário promovido pela OIT.

\section{Visões duais sobre o futuro do trabalho como pano de fundo}

Um oportuno exercício de confronto conceptual/argumentativo/linguístico e de sistematização de posições sobre as principais transformações do mundo do trabalho das últimas décadas foi proposto por Toni $(2003)^{2}$. De um lado, o fim do trabalho é ilustrado por meio de expressões que Toni (2003: 252-262) colhe de vários autores: "êxodo da sociedade salarial/não-classe de não-trabalhadores" (André Gorz), "trabalho não garante identidade" (Claus Offe), "fim do trabalho" (Jeremy Riflkin), "trabalhadores temporários permanentes” (Ulrick Beck), ou "só por acaso o trabalho cria laços sociais" (Dominque Méda). Do outro lado, Toni (2003: 262-274) reúne contributos mais condizentes com a centralidade do trabalho. Assim sendo, esta é vista como passível de ser reforçada, inclusive num contexto de trabalho digital em que as tecnologias têm um 
papel cada vez mais preponderante (na aceção de Manuel Castells). Além disso, o que se perdeu foi a consistência do trabalho e não a importância do trabalho (o argumento de Robert Castel). Ainda neste registo, Toni inclui Boaventura de Sousa Santos, para quem é imperativo um novo contrato social onde se incluam a redescoberta e partilha democrática do trabalho, o reconhecimento do seu poliformismo e a reinvenção do movimento sindical.

Este jogo de oposições definido num plano conceptual mais amplo pode igualmente ser observado quer quando se colocam "à prova” velhas profissões, quer quando se perspetivam novos empregos na economia digital. Por um lado, as velhas profissões estão sujeitas a distintos riscos no contexto da indústria 4.0: profissões relacionadas com o trabalho de escritório, vendas, comércio, logística, transporte, manufatura ou construção estão mais ameadas pela digitalização do que profissões ligadas à educação, artes, media, gestão de recursos humanos ou prestação de serviços de saúde. Por outro lado, poderá dizer-se que entre os novos empregos na economia digital não desaparecem as hierarquias: no "topo da escala" situam-se analistas e arquitetos de dados, especialistas em networking e inteligência artificial, designers e produtores de novas máquinas inteligentes, robots e impressoras 3D, especialistas em marketing digital e comércio eletrónico; na "base da escala" encontramos condutores da Uber, trabalhadores casuais (que fazem pequenas reparações, melhorias em casa, cuidado de animais) na economia "colaborativa", etc. (Degryse, 2016: 23). Esta hierarquização torna, pois, lícito argumentar que o futuro do trabalho assente em criatividade, remuneração e autonomia profissional não está (como de resto não esteve no passado) ao alcance de todos por igual, podendo por isso ser gerador de sentidos opostos (ainda que muitas vezes também complementares) de atração e de distanciamento.

Uma atividade laboral contemporânea com cada vez maior expressão e na qual é possível encontrar leituras de sentido oposto é o trabalho em call centers. A partir de uma análise da literatura sobre call centers, Costa e Costa (2018) identificaram: por um lado, estudos centrados nos processos de trabalho que decorrem em condições negativas, penalizadoras para quem aí trabalha a faceta fatalista dos call centers; por outro lado, estudos comparados onde, apesar da identificação de semelhanças e diferenças dentro e entre países, se analisam os call centers como espaços de otimismo e realização profissional - a faceta utópica dos call centers.

Perante a complexidade do fenómeno dos call centers, talvez seja mais prudente falar, na linha de Giddens (1984), não de um dualismo, mas de uma dualidade, tanto mais que não há propriamente uma literatura exclusiva do lado "mau" ou exclusiva do lado "bom" dos call centers. Assim, na literatura pessimista/realista - que tende a considerar os call centers como sinónimo de taylorização do trabalho de white-collar (Bain e Taylor, 2000) - reclamam-se sinais de "abertura" no sentido de "elevar/dignificar/qualificar" o trabalho 
aí realizado e de o dotar de mais força institucional, melhores enquadramentos normativos e capacidade de organização sindical (Lloyd, Weinkopf e Batt, 2010). De igual modo, também na literatura otimistalemancipatória - que enfatiza a redução dos processos de rotinização do trabalho por meio de tecnologias "multi-channel” (Batt, Holman e Holtgrewe, 2009), a valorização da criatividade, das qualificações e a mobilização potencial de um profissionalismo "a partir de baixo" (Vaidyanathan, 2012) - não deixam de se assinalar obstáculos inerentes ao trabalho em call centers, como, por exemplo, as dificuldades de organização sindical, o excesso de pressão sobre salários ou a fragmentação institucional.

Aliás, vários estudos comparativos (Holst, 2008; Doellgast, 2012; Doellgast, Sarmiento-Mirwaldt e Benassi, 2016) sugerem que estamos longe de cenários quer de plena convergência, quer de total divergência, pois os enquadramentos legais, os sistemas de relações laborais, os instrumentos de negociação coletiva, a qualificação da mão-de-obra ou o peso dos atores sindicais nunca são totalmente convergentes ou divergentes. Nesse sentido, não se poderá falar propriamente em futuros do trabalho uniformes apoiados num "regime laboral transnacional” aplicável às distintas realidades nacionais.

Como se observa a seguir, esse registo dualista sobre o futuro do trabalho que perpassa a literatura acaba por ser extensivo quer ao ambiente universitário, quer ao contexto sindical.

\section{Debater o futuro do trabalho a partir da academia}

$\mathrm{Na}$ linha da ILO Declaration on social justice for a fair globalization (ILO, 2008), o documento The future of work - centenary initiative (Ryder, 2015) estabeleceu quatro temas principais (os "diálogos do centenário") para pensar o futuro do trabalho: (i) trabalho e sociedade; (ii) empregos dignos para todos; (iii) organização do trabalho e da produção; (iv) e governação do trabalho. Obedecendo ao espírito tripartido da OIT - isto é, envolvendo representantes de governos, de empregadores e de trabalhadores - tal documento marcou, desde então, inúmeras reflexões nos planos mundial, regional e local.

A pertinência destes temas encontra fundamento nas múltiplas mudanças associadas ao mundo do trabalho, as quais se explicam por razões tecnológicas, demográficas (envelhecimento que coloca pressão aos sistemas de proteção social), bem como pelo aprofundamento da globalização, pelos processos migratórios (e obstáculos crescentes que lhes são colocados) ou pelas alterações climáticas. Por outro lado, por si sós, os cidadãos são incapazes de influenciar as mudanças em curso, pois "há forças que estão para além do controlo do indivíduo, as quais estão a determinar a direção do mundo do trabalho, não 
dispondo nós de meios para influenciar ou moldar esse futuro" (Ryder, 2017: 114). Por outro lado, a persistência de situações extremas - 200 milhões de pessoas no mundo sem trabalho; jovens com menos de 25 anos correm duas a três vezes mais riscos de ficar desempregados; 21 milhões de vítimas de trabalho forçado; 168 milhões de crianças a trabalhar (Ryder, 2017: 115; 138) evidencia um mundo cada vez mais injusto e desigual e faz com que a busca de critérios de justiça social se converta num imperativo civilizacional.

De par com estes problemas, o mundo do trabalho enfrenta, ainda segundo o diretor geral da OIT (Ryder, 2017: 139-140) outros desafios exigentes: 1) o fosso salarial entre géneros, que tende a ser relativamente menor quando os cidadãos acabam os seus percursos escolares ou universitários (no início de uma carreira profissional), mas que se torna maior à medida que as pessoas progridem numa vida de trabalho ao longo de anos, sendo ainda maior esse gender gap para os mais qualificados; 2) a gestão da diferença entre tipos de qualificações/competências com que cada um fica dotado quando frequenta uma escola ou universidade e aquelas que são requeridas no mundo do trabalho; 3) o desafio ambiental, associado à transição para um futuro baseado em baixas emissões de carbono que permita continuar na senda do trabalho decente para todos.

\subsection{Nota metodológica sobre uma simulação em ambiente universitário}

Tendo presente este pano de fundo de problemas e desafios, no ano letivo de 2016/2017, em resultado de uma cooperação interinstitucional entre a OIT (escritório de Lisboa), o Centro de Estudos Sociais da Universidade de Coimbra (CES-UC) e a Faculdade de Economia da Universidade de Coimbra (FEUC), organizou-se pela primeira vez num espaço europeu do ensino superior uma simulação da Conferência Internacional do Trabalho (CIT) da OIT (Costa, 2017). Tal simulação (designada de CIT-UC) implicou um trabalho de coordenação entre instituições, coordenações de cursos e uma seleção de 13 "dinamizadores" e, sobretudo, de 300 estudantes (“delegados"), maioritariamente estudantes de licenciatura (sobretudo de economia, sociologia, gestão e relações internacionais, mas igualmente de direito ou psicologia), incluindo também estudantes de mestrado e de doutoramento da UC.

Numa fase inicial, técnicos da OIT, docentes da FEUC e investigadores do CES cooperaram na seleção dos referidos "dinamizadores" (11 estudantes de doutoramento e 2 recém doutorados) que, por sua vez, seriam responsáveis pela coordenação das atividades e envolvimento dos estudantes em várias sessões de trabalho em comités. A experiência pedagógica (que combinou ensino e aprendizagem) foi, pois, sobretudo protagonizada por estudantes universitários, ainda que vários docentes da FEUC tenham também incorporado nos 
programas de disciplinas conteúdos temáticos diretamente relacionados com os "diálogos do centenário" da OIT acima referidos, desde logo o citado documento The future of work.

Ora, foi precisamente inspirada nesse documento e respeitando o tripartismo da OIT, que a CIT-UC se organizou em 4 comités temáticos: macro-regulação económica do emprego; mudanças tecnológicas e trabalho; trabalho e desigualdades; futuro das relações de trabalho. A cada comité temático foi associado não só um conjunto de temas e problemas, como sobretudo um conjunto de propostas desde logo resultantes do "encontro de vontades" entre delegados (colocados "na pele" de representantes de governos, empregadores e trabalhadores).

\subsection{Temas e propostas da CIT-UC}

Um breve olhar sobre a identificação dos problemas, i.e., da agenda de questões de possível debate inerentes a cada comité temático, bem como sobre as propostas para a sua resolução é reveladora do modo como os jovens universitários, mesmo que sob uma simulação, enfrentam com realismo o mundo do trabalho e perspetivam nele vários futuros. Por um lado, ao recuperarem temas, dão conta de problemas que norteiam cada comité temático. Por outro, ao proporem soluções, projetam o futuro sob múltiplas formas.

1. O comité macro-regulação económica constitui um apelo à perceção do lugar da política económica na promoção do crescimento, na criação e na qualidade do emprego. A "era da austeridade" que Portugal e o processo de desvalorização interna que lhe ficou associado, foram matérias em discussão. Como o foram também o endividamento público e privado, as desigualdades de rendimentos, o comportamento do setor financeiro, ou a substituição do "pleno emprego" pela "plena empregabilidade”, no campo das políticas públicas.

De entre as propostas sugeridas pelos delegados salienta-se: a recomendação da criação de um fundo internacional para a criação de emprego (gerido pela OIT), partindo do modelo do Fundo Social Europeu; a penalização de formas de especulação financeira e a taxação de setores menos taxados da economia internacional; o convite (aos Estados membros) para estimularem as empresas à criação de mecanismos voluntários de promoção de empregos de qualidade para além dos mínimos considerados admissíveis, quer distinguindo empresas com "selo" de garantia da promoção do trabalho digno (em matéria de rendimento, tempos de trabalho, realização de trabalhadores), quer publicitando e denunciando empresas seguidoras de más práticas laborais.

2. O comité relativo aos impactos das mudanças tecnológicas no trabalho e no emprego suscitou um misto de sentimentos de atração e repulsa. As conversações centraram-se em aspetos como: o papel das indústrias do futuro; 
os diferentes tipos de trabalho digital; as implicações da automação produtiva na vida de quem trabalha; a interferência dos processos de individualização na gestão dos tempos de trabalho e do não-trabalho; o desemprego tecnológico; as exigências de novas competências; as tensões entre atividades de serviço público tradicional e o recurso a plataformas tecnológicas (de que o conflito entre taxistas e as plataformas Uber ou Cabify são apenas um exemplo).

De entre as propostas sugeridas pelos delegados destaca-se: o incentivo à formação e requalificação/especialização de trabalhadores (em vez de despedimento); a concessão de isenção fiscal a empresas não lucrativas (reduzindo riscos de encerramento de atividades e de extinção de postos de trabalho); a defesa de uma maior articulação entre o sistema de ensino universitário e as necessidades do mercado de trabalho (ajustando vagas universitárias a necessidades reais, atualizando práticas de ensino e conteúdos programáticos, reforçando a componente tecnológica das instituições de ensino ou apostando no ensino profissionalizante como forma de dotar os futuros trabalhadores de maiores competências técnicas e de maior atratividade); a limitação à introdução de máquinas sempre que estas substituam pessoas; o reforço do investimento público na criação de incubadoras tecnológicas de economia solidária em universidades, comunidades e organizações sociais.

3. O comité centrado na problemática das desigualdades no trabalho e no emprego abordou questões como: as desigualdades de género, traduzidas em persistentes assimetrias salariais ou de acesso a lugares de responsabilidade nas empresas; a perceção do fosso cavado entre formas de trabalho atípicas (contratação a termo, recibos verdes, trabalho a tempo parcial, temporário, à peça, etc.) e desigualdades de rendimento e de acesso a direitos laborais e sociais; os novos desafios se apresentam à gestão de "recursos humanos" nas organizações.

Quanto às propostas avançadas neste comité, destacou-se: a necessária renovação de ordenamentos jurídicos para melhor regular as novas formas de trabalho; a valorização do salário mínimo; a adoção de medidas de reforço da igualdade de género, tais como: maior equilíbrio entre a vida familiar e a vida profissional; eliminação de barreiras no acesso ao emprego e à progressão na carreira, propondo um sistema de quotas atribuídas às mulheres para lugares de chefia das empresas (30\% nas micro e pequenas empresas, $40 \%$ nas médias e $50 \%$ nas grandes); introdução de conteúdos formativos obrigatórios sobre igualdade de género, tanto nos curricula escolares (do ensino básico ao superior), como em contexto empresarial, para trabalhadores e empregadores; fiscalização e coimas reforçadas em caso de incumprimento das medidas de combate à desigualdade de género.

4. Last but not least, o comité sobre o futuro das relações laborais centrou-se no modo como se devem manter ativas as estratégias de diálogo/confronto/ compromisso entre representantes de governos, empregadores e trabalhadores 
para que o trabalho, sendo um espaço de responsabilização e de dever profissional, seja crescentemente um locus de realização e valorização pessoal, de criatividade, de efetivação da democracia. O papel do diálogo social em geral, e da negociação coletiva em particular, assumiram aqui uma centralidade inquestionável no sentido de comprometer interesses diferentes.

Em termos propositivos, os delegados da CIT-UC defenderam relações laborais respaldadas por quadros regulamentares que assegurem a defesa e proteção de direitos. Desde logo, combatendo a precariedade e apoiando medidas como: limitação do período experimental a 45 dias; redução da jornada de trabalho; reforço da voz coletiva de trabalhadores nas empresas; sancionamento do recurso ao falso trabalho autónomo; estímulo ao acolhimento e integração socioprofissional de imigrantes e refugiados; reforço dos incentivos à contratação coletiva.

\section{Perspetivas sindicais setoriais sobre o futuro do trabalho na indús- tria 4.0}

Um dos debates que porventura mais deixa inquietos velhos atores como os sindicatos - afinal as entidades que esgrimem uma "espada da justiça” em favor dos fracos e desfavorecidos (Gumbrell-McCormick e Hyman, 2013; Hyman, 2016) - são as questões relativas à inovação e ao mundo da indústria 4.0 (ICTUR, 2018). Como se viu na seção anterior, esse era o foco de um dos debates promovido pela CIT-UC. E essa é hoje uma questão tão crucial quanto se sabe que os desenvolvimentos mais recentes associados aos processos de digitalização do trabalho assentam nos seguintes pontos bem destacados por Degryse (2016: 7): (i) internet e redes de alta velocidade; (ii) quantidades enormes de dados comerciais, pessoais e geográficos (os designados Big Data) que são incorporados pelas plataformas da internet de modo a estarem disponíveis e poderem ser utilizados instantaneamente; (iii) profusão de novas formas de dispositivos móveis que dão acesso à internet móvel.

\subsection{Contributos de uma pesquisa empírica: recorte metodológico}

As perceções de responsáveis sindicais portugueses no quadro das tendências da indústria 4.0 foi captada como parte dos objetivos do projeto de investigação "Rebuilding trade union power in the age of austerity: a review of three sectors" (Costa et al., 2019). Nesse projeto procurou-se avaliar a efetividade das formas de poder sindical em resultado da era da austeridade que, na 
sociedade portuguesa, teve o seu ponto mais alto aquando da intervenção da troïka (Fundo Monetário Internacional, Banco Central Europeu e Comissão Europeia). Tendo decorrido entre junho de 2016 e março de 2019, o referido projeto apresentou uma incidência setorial e conferiu destaque às organizações sindicais atuantes no "radar" de três empresas multinacionais: a Autoeuropa (setor metalúrgico), a Tap Air Portugal (setor dos transportes) e a Portugal Telecom/Altice (atual Altice Portugal) (setor da telecomunicações) ${ }^{3}$. Por cada estudo de caso, foram realizadas quinze entrevistas semiestruturadas, embora tenham também sido entrevistados outros protagonistas de relevo ligados a organizações sindicais internacionais. Complementarmente, foi ainda conduzido um focus group para cada um dos estudos de caso.

Ainda que o critério da "inovação" tenha sido apenas um dos critérios sobre os quais os representantes sindicais foram interrogados ${ }^{4}$, este é um critério particularmente oportuno, especialmente num movimento sindical (como o português) ainda muito marcado por práticas “antigas”: excesso de presença masculina (tanto no topo como na base da hierarquia sindical); excessiva proximidade/dependência face aos partidos políticos; défice de qualificação dos filiados sindicais em geral; divisões ideológicas; taxas de sindicalização relativamente baixas; foco tímido no cyberativismo das redes sociais, etc.

\subsection{Perceções sindicais sobre a "inovação"}

$\mathrm{Na}$ linha dos debates sobre o futuro do trabalho e sobre algumas profissões e formas de trabalho contemporâneas antes abordados, quando confrontados com o desafio da "inovação", representantes sindicais nos três setores expressaram sentimentos otimistas (associados a potencialidades), mas sobretudo sentimentos pessimistas (associados a resultados).

\footnotetext{
3 Ainda que no contexto deste artigo não se forneçam ilustrações de todos os discursos dos representantes sindicais entrevistados, importa pelo menos assinalar a lista das organizações a que pertencem tais representantes. Assim, no contexto envolvente da Autoeuropa foram realizadas entrevistas a representantes da Federação Intersindical das Indústrias Metalúrgicas, Químicas, Elétricas, Farmacêutica, Celulose, Papel, Gráfica, Imprensa, Energia e Minas (Fiequimetal) e do Sindicato dos Trabalhadores das Indústrias Transformadoras, Energia e Ambiente do Sul (Site-Sul). No contexto da TAP, foram entrevistados representantes do Sindicato Nacional do Pessoal de Voo da Aviação Civil (SNPVAC), do Sindicato dos Trabalhadores da Aviação e Aeroportos (SITAVA) e do Sindicato dos Técnicos de Manutenção e Aeronaves (SITEMA). Por fim, na PT/Altice foram entrevistados representantes do Sindicato Nacional dos Trabalhadores das Telecomunicações e Audiovisual (SINTTAV), do Sindicato dos Trabalhadores do Grupo Portugal Telecom (STPT), do Sindicato Nacional dos Trabalhadores de Correios e Telecomunicações (SNTCT) e do Sindicato Democrático dos Trabalhadores das Comunicações e dos Media (SINDETELCO).

4 Além da inovação, no projeto já citado foram testados outros cinco critérios de análise como forma de captar os principais espaços onde o sindicalismo poderá estar a recuperar poder: "representatividade"; "qualificação"; "conflito/negociação"; "nacional/internacional”; "público/privado” (Costa et al., 2019).
} 
De um ponto de vista mais otimista, são vários os aspetos associados ao contributo das tecnologias para o trabalho ou com os quais os entrevistados manifestaram concordância:

- a internet ajuda as organizações a comunicarem de maneira mais rápida e barata com um público mais amplo e a criar arquivos digitais de livros, revistas, panfletos e outros materiais desenvolvidos por organizações de trabalhadores em todo o mundo, no que há 15 anos já Eric Lee designava de global labournet, convertida na "primeira organização de trabalhadores verdadeiramente global” (Lee, 2004: 71);

- os esforços de mobilização tornaram-se mais evidentes através da capacidade de transmitir informações em tempo real, assim como de denunciar violações dos direitos dos trabalhadores, enviar apelos à ação ou aumentar a consciencialização sobre matérias de interesse laboral;

- na indústria 4.0 os trabalhadores podem ganhar mais autonomia e realizar trabalhos mais interessantes e menos árduos;

- existe uma maior flexibilidade e conciliação entre emprego e vida familiar;

- "um bom site resolve a questão do declínio de sindicalizados, bem como o formato e o nível de comunicação" (ex-dirigente do SITAVA, entrevista, 18 de janeiro de 2018);

- "As cores, o lettering, tudo isso conta. Nós temos dois elementos da direção entre os 30 e os 35 anos que dominam as tecnologias, fizeram eles próprios, em colaboração com empresas especializadas, o desenho do novo logotipo do sindicato (...) conseguiram uma aplicação no telemóvel, há um facebook que funciona maravilhosamente e é do agrado de todos porque é praticamente em simultâneo, aquilo é pergunta/resposta em simultâneo. É mais fácil através do facebook serem esclarecidos seja de qualquer dúvida, seja de qualquer assunto laboral" (vice-presidente do sindicato nacional dos trabalhadores da aviação civil, SNPVAC, entrevista, 18 de janeiro de 2018).

Por outro lado, porém, esta faceta otimista parece recorrentemente ser ultrapassada por um pessimismo de contornos realistas, pois são vários os desafios que ainda há a superar: iliteracia digital; défice democrático no local de trabalho, que limita o acesso dos trabalhadores à internet; restrições em matéria de tradução para distintos idiomas para que se pudesse falar numa rede de trabalho verdadeiramente global; um ambiente excessivamente competitivo e muito marcado pela obtenção de dados; défices de atualização de sites das organizações, etc. Além disso, uma explicação adicional para as reservas manifestadas pelos sindicalistas reside no "efeito cruzado da precarização e digitalização" (Costa, 2018: 597). No quadro de uma "revolução tecnológica plena” (Valenduc e Vendramin, 2016: 19), as novíssimas tecnologias (nuvem, Big Data, aplicações móveis, geolocalização, a internet das coisas e os robots móveis, etc.) produzem implicações sobre a organização do trabalho (Vandaele, 
2018), reconfiguram identidades profissionais e diminuem as oportunidades de organização coletiva no plano sindical.

Em boa verdade, os receios sindicais fazem-se sentir, desde logo, ao nível das principais confederações sindicais portuguesas. Por um lado, a Confederação Geral dos Trabalhadores Portugueses (CGTP) tende a assumir claramente uma postura de denúncia da digitalização, robotização e mecanização, as quais são vistas como sinónimo de precariedade e individualização. Nestes termos, o trabalho humano é considerado insubstituível. Por outro lado, a União Geral de Trabalhadores (UGT), apesar de assumir uma postura mais moderada, alerta para a necessidade de a tecnologia não poder pôr em causa a função social do trabalho ${ }^{5}$.

Mas os seguintes extratos de entrevistas setoriais resultantes do projeto supramencionado são ainda mais ilustrativos de perceções e vivências subjetivas defensivas face à era digital:

"Aquilo [facebook] ainda é um bocado uma brincadeira no anonimato. Qualquer pessoa pode criar um perfil anónimo e espalhar um boato. É preferível comunicar através de uma mailing list como forma de garantir que sabemos quem é a pessoa que está do outro lado!” (Entrevista com representante do SITEMA, 14 de junho de 2018).

“Até hoje, publiquei poucas respostas no facebook. Se vejo uma pessoa a colocar uma questão que acho que até é pertinente, mando-lhe uma mensagem pessoal dizendo que o assunto não deve ser discutido por detrás de um teclado. Ligo-lhe para falarmos pessoalmente. Não gosto de ficar atrás de um teclado" (secretário nacional do SINDETELCO, entrevista, 14 de fevereiro de 2018

Esta citação significa que as elevadas expectativas colocadas no sindicalismo digital requerem intervenção direta, uma ideia partilhada por um líder sindical português de uma federação sindical europeia, igualmente entrevistado. Apesar de ser internacionalista e utilizador de tecnologias digitais, reforçou que:

“A questão das Internetes e dos blogs e dos WhatsApp e tudo isso não pode substituir o envolvimento físico com os trabalhadores, o trabalhar junto com eles para conhecer os seus problemas. Até mesmo os sindicatos nórdicos que são conhecidos pelos altos níveis de sindicalização, vêm-nos contar nas nossas reuniões que estão a descobrir uma nova forma de trabalhar que é estar junto dos trabalhadores, encontrá-los à saída das fábricas, às vezes ir aos bares onde

5 Para uma análise dos discursos dos respetivos representantes sindicais "de topo" sobre esta matéria, cf. Costa (2017: 85-92). 
eles se encontram no local onde vivem (Secretário Geral da Federação Europeia dos Trabalhadores em Transportes, ETF, entrevista, 12 de janeiro de 2018).

As citações anteriores evidenciam que, apesar dos instrumentos da era digital (web, email, facebook, etc.) se poderem constituir em ferramentas fundamentais de recrutamento e mobilização sindical, o sindicalista "virtual" ainda está muito aquém do sindicalista "real" (Costa, 2018). Mesmo que seja crescente, um pouco por todo o mundo, o número de organizações sindicais que possuem um endereço eletrónico e que põem os seus associados a comunicar $\mathrm{em} / \mathrm{na}$ rede, seria certamente de grande utilidade proceder a um cyber-censo mundial que permitisse medir a dimensão do acesso à internet por parte dos sindicalistas, desde logo porque existem diferenças entre países, setores e sindicatos, assim como existem diferentes intensidades de valorização da rede, distintos timings de atualização das páginas eletrónicas, etc. (Rego et al., 2014). A ideia seria tão-só a de criar condições para verificar, como assinalava Eric Lee na viragem do século XX para o século XXI, se "o número de sindicalistas on line é pelo menos tão elevado quanto a percentagem de sindicalistas numa determinada sociedade" (Lee, 2000: 14). E, mais do que isso, seria útil verificar qual o peso da mobilização eletrónica na produção de efeitos reais favoráveis para os trabalhadores. $\mathrm{Na}$ verdade, como assinalava mais recentemente Lee, ainda que algumas tecnologias (como o email) contem mais do que outras (facebook), o que realmente interessa é saber se os sindicatos estão realmente preparados para mobilizar os seus próprios membros e a encorajá-los a perder alguns segundos a assinar e apoiar campanhas (Lee, 2018). É de mobilização sindical para a era digital que continua a precisar-se.

\section{Conclusão: 0 imperativo da regulação como via para emancipar 0 trabalho}

Ao longo do texto foi possível constatar que o futuro do trabalho enfrenta realidades complexas que fazem dele, como de qualquer futuro, uma realidade incerta e plural. Os debates teóricos deambulam entre visões otimistas (por vezes mesmo utópicas) e visões pessimistas (porventura mais realistas) e são, nessa medida, uma boa ilustração dessa incerteza e pluralidade. Ainda assim, nenhuma das visões, sejam as mais otimistas sejam as mais pessimistas, é exclusivista da linha de pensamento que defende ou em que acredita como sendo a única digna de crédito.

$\mathrm{Na}$ linha do pensamento da OIT e da celebração do seu centenário, nada melhor do que colocar os jovens e debater e a projetar o futuro do trabalho (que 
na verdade é o seu futuro) em múltiplas vertentes. Foi disso que também se deu conta ao retomar quer os problemas, quer as propostas associadas ao mundo do trabalho em matérias como a macro-regulação económica do emprego, as mudanças tecnológicas, as desigualdades e as relações de trabalho. Entre um público universitário jovem, e corroborando os debates teóricos, também a mistura de sentimentos, dúvidas e hesitações sobre o futuro do trabalho marcou presença, tanto mais que, ao colocarem-se "na pele" de empregadores, trabalhadores e governos, a maior parte deles não conhece ainda, por dentro, a realidade laboral concreta porque não a vivenciou. Mas esse exercício de identificação subjetiva com "o outro" é também uma condição indispensável para a autocrítica. E é porventura também um requisito fundamental para que a apresentação de propostas concretas sobre o futuro do trabalho - assentes em leituras prévias, em confrontos de argumentos, e na construção de consensos assuma um caráter propositivo e não tão temerário.

Do ponto de vista dos olhares sindicais, a projeção dos futuros do trabalho - mormente na questão específica da relação entre trabalho e tecnologia - suscitou sinais de maior ambiguidade e receio. A que não será alheia a dificuldade em superar velhas práticas e hábitos instalados e onde o contacto face a face com os trabalhadores, por ser prioritário, só de forma progressiva dará lugar a novos meios de atuar por via da "mão" tecnológica. O alerta para os perigos decorrentes do uso das tecnologias ao serviço do trabalho, e, sobretudo, o receio de que as máquinas tomem o lugar do ser humano, é ainda uma ideia muito presente entre os sindicalistas portugueses dos setores analisados. O que, em boa medida, é um reflexo da influência ditadas dos discursos das principais confederações sindicais em Portugal e da sua orientação "de cima para baixo".

Torna-se, pois, necessário pensar o futuro do trabalho corrigindo, melhorando e propondo instrumentos regulatórios adequados. Nas propostas dos delegados da CIT-UC, várias sugestões apontaram precisamente no sentido de compromissos regulatórios efetivos. Algumas delas (como se constatou) são porventura até demasiado ousadas. No entanto, vão ao encontro dos imperativos de ordem política que lhes subjazem. No caso português, nos dois últimos ciclos políticos (quer entre 2011 e 2015/Governo PSD/CDS, quer entre 2015 e 2019/Governo PS apoiado por BE e PCP, a célebre "geringonça") transitou-se de um período de algum aprisionamento normativo (de que a lei 23/2012 é um bom exemplo, pois complementou/validou a presença da troika em Portugal) para um período em que os enquadramentos normativos puderam incorporar um viés mais emancipatório: a lei 63/2013 que institui os mecanismos de combate à precariedade e que seria reforçada pela lei 55/2017; ou a lei 112/2017, que instituiu o Programa de Regularização Extraordinária de Vínculos Precários na Administração Pública (PREVPAP), são apenas dois exemplos 
dos progressos alcançados, apesar do caminho que ainda há a percorrer (Leite, 2018; ILO, 2018).

Por sua vez, os representantes sindicais entrevistados parecem clamar pela introdução de mecanismos regulatórios ajustados às novas formas de trabalho da indústria 4.0 (como o crowdwork). Além de, como adverte D. Méda (2016), ajudarem a superar a diluição de fronteiras entre trabalho e não trabalho, entre público e privado ou entre baixo e elevado custo de produção de bens, tais mecanismos apontam caminhos para um futuro do trabalho mais emancipatório, assente: no reconhecimento da existência de uma relação de emprego subordinada em que a plataforma online funcione ou como "intermediária" ou como "empregador"; na garantia de uma remuneração decente e condições de trabalho justas; na obrigação legal de garantia de mecanismos de monitorização (Körfer e Röthig, 2017). Esse suporte legal mínimo, por ora deficitário, ajudará certamente a criar condições para que a visão sindical futura sobre a relação entre trabalho e tecnologia se afigure menos temerária e, como tal, digna de maior confiança.

\section{Referências bibliográficas}

BAIN, Peter and Phil Taylor (2000), “Entrapped by the 'electronic panopticon'? Worker resistance in the call center." New Technology, Work and Employment, 15, 2-18.

BATT, R., Holman, D.M; Holtgrewe, U. (2009), "The globalization of service work: Comparative institutional perspectives on call centers (Introduction to a Special Issue)". Industrial \& Labor Relations Review, 62 (4), 453-488.

COSTA, Hermes Augusto (org.) (2017), O futuro do trabalho em debate: simulação da Conferência Internacional do Trabalho na Universidade de Coimbra. Coimbra: Imprensa da Universidade de Coimbra.

COSTA, Hermes Augusto (2018), "Work and technology: student and union perceptions in Portugal”, International Union Rights, 25 (3), 22-23.

COSTA, Hermes Augusto; COSTA, Elizardo Scarpati (2018), "Precariousness and call centre work: Operators' perceptions in Portugal and Brazil”, European Journal of Industrial Relations, 24 (3), 243-259.

DEGRYSE, Christophe (2016), "Digitalisation of the economy and its impact on labour markets”, Working Paper 2016/02. Brussels: European Trade Union Institute.

DOELLGAST, V., SARMIENTO-MIRWALDT, K., \& BENASSI, C. (2016), "Contesting Firm Boundaries Institutions, Cost Structures, and the Politics of Externalization”. ILR Review, 69 (3), 551-578.

DOELLGAST, Virginia (2012), Disintegrating democracy at work: labor unions and the future of good jobs in the service economy. Cornell University Press.

ESTANQUE, Elísio; COSTA, Hermes Augusto (2018), "Trabalho e desigualdades no século XXI: velhas e novas linhas de análise”, Revista Crítica de Ciências Sociais, Número Especial (edição comemorativa dos 40 anos), 261-290.

ESTANQUE, Elísio; COSTA, Hermes Augusto; FONSECA, Dora; SANTOS, Andreia (2018), "Digitalização e precariedade laboral: novos desafios para o sindicalismo e os movimentos sociais no contexto português", Século XXI, Revista de Ciências Sociais, 8 (2), 589-621. 
GIDDENS, Anthony (1984), The constitution of society: outline of the theory of structuration. Cambridge: Polity Press.

GUMBRELL-MCCORMICK, Rebecca; HYMAN, Richard (2013), Trade unions in Western Europe: hard times, hard choices. Oxford: Oxford University Press.

HOLST, Hajo (2008), "The political economy of trade union strategies in Austria and Germany: The Case of Call Centres", European Journal of Industrial Relations, 14 (1), 25-45

HYMAN, Richard (2016), "The very idea of democracy at work", Transfer - European Review of Labour and Research, 22 (1), 11-24.

ICTUR (2018), “Focus on Industry 4.0”, International Union Rights (2018), vol. 25 (3).

ILO (2008), ILO Declaration on social justice for a fair globalization (adopted by the 97th session of the International Labour Conference. Geneva: International Labour Office.

ILO (2018), Decent work in Portugal, 2008-2018: from crisis to recovery. Geneva: International Labour Office.

KÖRFER, Aileen; RÖTHIG, Oliver (2017), "Decent crowdwork - the fight for labour law in the digital age", Transfer - European Review of Labour and Research, 23 (2), 233-236.

KOVÁCS, Ilona (2012), "Trabalho, emprego e organizações na era da globalização: controvérsias”, in Fernando Bessa Ribeiro, Manuel Carlos Silva, Ana Paula Marques (orgs.), Trabalho, técnicas e mundo: perspetivas e debates. Vila Nova de Famalicão: Húmus, 39-59.

LEE, Eric (2000), The Internet belongs to every one (http://www.labourstart.org/icann/ericleebook.shtml).

LEE, Eric (2004), “Towards global networked unions”, in R. Munck (ed.), Labour and globalisation: results and prospects. Liverpool: Liverpool University Press, 71-82.

LEE, Eric (2018), "Digital solidarity or complacent clicktivism?”, International Union Rights, 25 (3), 24-25.

LEITE, Fausto (2018), “Contradições na legislação laboral”, Público, 45.

LLOYD, C., Weinkopf, C., \& Batt, R. (2010), "Restructuring customer service: labor market institutions and call center workers in Europe and the United States". Low-Wage Work in the Wealthy World: 421-466.

MÉDA, Dominique (2016), The future of work: The meaning and value of work in Europe. Geneva: International Labour Office.

REGO, Raquel; Alves, Paulo Marques; Naumann, Reinhard; Silva, Jorge (2014), “A typology of trade union websites with evidence from Portugal and Britain", European Journal of Industrial Relations, 20 (2) 185-195.

RUSSELL, Bob (2008), “Call centres: A decade of research”, International journal of management reviews, 10 (3), 195-219.

RYDER, Guy (2015), The future of work - centenary initiative (Report of the Director-General, Report I/ International Labour Conference, 104th Session). Geneva: International Labour Office.

RYDER, Guy (2017), “Intervenção do Diretor-Geral da OIT” e "Comentários do Diretor-Geral da OIT em resposta às intervenções dos delegados/as”, in Hermes Augusto Costa (org.), O futuro do trabalho em debate: simulação da Conferência Internacional do Trabalho na Universidade de Coimbra. Coimbra: Imprensa da Universidade de Coimbra, 112-119; 136-140.

TONI, Míriam de (2003), "Visões sobre o trabalho em transformação”, Sociologias, 9, 246-286.

VAIDYANATHAN, Brandon (2012) "Professionalism 'from below': the mobilization potential of Indian call centres”, Work, Employment and Society, 26 (2), 211-227.

VALENDUC, Gérard; VENDRAMIN, Patricia (2016), “Work in the digital economy: sorting the old from the new", Working Paper 2016/03. Brussels: European Trade Union Institute. 
VANDAELE, Kurt (2018), "Will trade unions survive in the platform economy? Emerging patterns of platform workers' collective voice and representation in Europe”. Working Paper 2018/05. Brussels: European Trade Union Institute. 